\title{
O CONCEITO DE ANGÚSTIA NO PENSAMENTO PÓS-METAFÍSICO
}

\section{The Concept of Anxiety in the Pos-Metaphysical Thought}

\section{Resumo}

Eder Soares Santos ${ }^{1}$

Pretendemos, neste artigo, traçar alguns pontos de intersecção entre 0 conceito de angústia na psicanálise de Winnicott e a fenomenologia existencial de Martin Heidegger, a fim de mostrar que a psicanálise winnicottiana se insere num contexto pós-metafísico. Para tanto, apresentaremos um esboço da análise fenomenológica do sentido do ser em Heidegger. Em seguida, apresentaremos alguns pontos de afinidades entre esse pensamento fenomenológico e a psicanálise winnicottiana. E, finalmente, desenvolveremos a tese de que é possível aproximar o conceito de angústia nesses dois autores.

Palavras-chave: Angústia; Fenomenologia existencial; Pós-metafísica; Psicanálise winnicottiana.

\section{Abstract}

We intend, in this article, to trace some intersecting points between the concept of anxiety in Winnicott's psychoanalysis and Martin Heidegger's existential phenomenology to show that Winnicottian psychoanalysis is inserted in a post-metaphysical context. To achieve that, we present a draft of the phenomenological analysis of the sense of being in Heidegger. Next, we present some points of affinity between that phenomenological thought and Winnicottian psychoanalysis and we finally develop the thesis that it is possible to approximate the concept of anxiety of both authors.

Keywords: Anxiety; Existential phenomenology; Post-metaphysics; Winnicottian psychoanalysis

${ }^{1}$ Doutorando em Filosofia - UNICAMP. Bolsista: DAAD/CNPq. E-mail:edersan@hotmail.com

Revista de Filosofia, Curitiba, v. 17 n.20, p. 45-66, jan./jun. 2005. 


\section{Introdução}

Pretendemos, neste artigo, traçar alguns pontos de intersecção entre o conceito de angústia na psicanálise de Winnicott e a fenomenologia existencial de Martin Heidegger. Ora, já de saída, poder-se-ia perguntar. é possível realizar tal investida, já que a angústia de que Heidegger trata, especialmente em Ser e Tempo, não parece, à primeira vista, ser a mesma de que trata a psicanálise winnicottiana? Dito de outra forma, o que faz Heidegger é tratar da questão da angústia no nível ontológico, enquanto os psicanalistas tomam a angústia pela perspectiva ôntica. Logo, como proceder?

Essas questões que se nos colocam primeiramente serão, em verdade, as últimas a serem respondidas. Acreditamos que, antes de abordá-las, um certo percurso deva ser realizado até que atinjamos a clareira da nossa empreitada.

Sendo assim, precisamos: 1) perceber o que há de importante na questão do sentido do ser, tal como analisada por Heidegger para a psicanálise; 2) observar quais as afinidades que podem existir entre o pensamento pós-metafísico de Heidegger e a psicanálise não-metapsicológica de Winnicott e, finalmente; 3) tentar mostrar como entender a questão da angústia tanto no nível ôntico como ontológico na psicanálise.

\section{Menschsein: ser acontecente}

Heidegger, em sua tentativa de interpretar o existir humano, coloca uma pergunta que desde muito tempo é conhecida pela filosofia, qual seja: ele pergunta pelo que é o homem. Todavia, pergunta pelo homem destituído de seus afazeres, isto é, não pergunta pelo agir como até então acontecera na metafísica. Para Heidegger, em Ser e Tempo, a questão que se coloca é a do ser (Sein) ou, mais propriamente, a pergunta é pelo sentido do ser. Porém, perguntar-se-ia, com o quê ou com quem essa questão pelo sentido do ser se relaciona. Em Heidegger: com o ente. "Chamamos de 'ente' [seind"] muitas coisas em sentidos diversos.

* Faremos uso da tradução brasileira de Ser e Tempo (2000), cotejada com o original em alemão, Sein und Zeit (Gesamtausgabe, vol. 2, Vittorio Kloestermann, Frankfurt, 1977). Por isso, seguir-se-á a numeração de ambas as edições. Assim, a numeração que aparece após o ponto e vírgula refere-se ao texto em alemão.

Revista de Filosofia, Curitiba, v. 17 n.20, p. 45-66, jan./jun. 2005. 
Ente é tudo de que falamos, tudo que entendemos, com que nos comportamos dessa ou daquela maneira, ente é também o que e como nós mesmos somos" (HEIDEGGER, 2000, p. 32; HEIDEGGER, 1977, p. 9; 10;33).

O ente, alvo das nossas preocupações aqui, é aquele "que possui em seu ser a possibilidade de questionar" (HEIDEGGER, 2000, p. 33; HEIDEGGER, 1977, p.10). Este ente pode ser designado pelo termo estar-aí (Dasein) ou por sua presença. Isto é, a questão do sentido do ser é uma questão do ser do ente, isto é, uma questão do ser do homem. Em outras palavras, a pergunta é: o que é o homem?

O estar-aí é um modo de ser privilegiado, pois é o único que, em sendo, coloca em jogo o seu próprio ser e estabelece uma relação de ser com seu próprio ser, ou seja, do ponto de vista ôntico, o homem que é pode compreender a si mesmo, sendo. Essa compreensão remete o ser a um questionamento ontológico.

Assim, assuma ou não a sua responsabilidade de compreensão de si mesmo, essa possibilidade só pode se tornar possível a partir de cada estar-aí em si mesmo. Abre-se, então, a perspectiva, de onde outras podem surgir, tanto para uma ontologia fundamental, quanto para uma analítica existencial do estar-aí (HEIDEGGER, 2000, p. 39-40; 17-18).

O estudo da questão do ser em Heidegger não se orienta pelo acaso. Ele segue um método fenomenológico de interpretação. Para Heidegger (2000, p. 57; 37) essa fenomenologia se exprime por deixar aparecer as coisas em si mesmas e também por um modo de investigação que se define negativamente: "não se deve aplicar, de maneira dogmática uma idéia (Idee) qualquer de ser e realidade (Wirklichkeit) por mais 'evidente' que seja. Nem se deve impor ao estar-aí 'categorias' delineadas por aquela idéia." (HEIDEGGER, 2000, p. 44; 23).

A investigação do sentido do ser deve-se dar na cotidianidade mediana (durchschnittliche Alltäglichkeit), pois é "antes de tudo e na maioria das vezes”, como o estar-aí se mostra (HEIDEGGER, 2000, p. 44; 23). O questionamento pelo ser também vai estar limitado pela temporalidade (Zeitlichkeit), pois "o tempo é o ponto de partida do qual o estar-aí sempre compreende e interpreta implicitamente o ser" (HEIDEGGER, 2000, p. 45; 24).

Para que uma tal compreensão de ser em si mesmo possa ocorrer, é preciso, antes de tudo, livrar-se do aguilhão da tradição metafísica. Procedendo, assim, a sua destruição. "Entendemos essa tarefa como destruição [Destruktion] do acervo da antiga ontologia, legado pela tradição” (HEIDEGGER, 2000, p. 51; 30).

Revista de Filosofia, Curitiba, v. 17 n.20, p. 45-66, jan./jun. 2005. 
É com esse pano de fundo que poderemos tentar ver o que há de importante para a psicanálise quanto a este questionamento pelo sentido do ser. Ora, parece-nos que o ser-homem é tomado por Heidegger numa perspectiva outra que não mais a da tradição metafísica. Por isso, a questão do homem, sujeito na psicanálise, também há de tomar um outro rumo. Tentemos observar se tal possibilidade ocorre.

A essência do estar-aí consiste no seu próprio ser, em sua existência. Existência, aqui, não entendida como ser simplesmente dado (Vorhandenheit) da ontologia tradicional, mas caracterizada pelos seus modos possíveis de ser (HEIDEGGER, 2000, p. 77; 56). A caracterização do estar-aí exige, já e desde sempre, o caráter de pessoalidade, pois "o ser, que está em jogo no ser deste ente, é sempre meu" (HEIDEGGER, 2000, p. 78; 57). O estar em jogo relaciona-se com o ser na sua possibilidade mais própria. "O estar-aí é sempre sua possibilidade" (HEIDEGGER, 2000, p. 78; 57). Possibilidade esta que permite ao ser, em sendo, poder ser próprio (eigentlich) ou impróprio (uneigentlich), ou seja, pode "escolher-se, ganhar-se ou perder-se ou ainda nunca ganhar-se ou só ganharse 'aparentemente'" (HEIDEGGER, 2000, p. 78; 57).

O estar-aí, segundo Heidegger, não pode, ou pelo menos não deveria, ser objetivado, mesmo que ele se encontre inserido na cotidianidade mediana, sendo (existindo) de modo impróprio, fugindo e se esquecendo de si mesmo (HEIDEGGER, 2000, p. 80; 59).

O estar-aí, próprio ou impróprio, que se encontra na cotidianidade deve ser compreendido já estando, de antemão, em um mundo. Por isso, é permitido dizer que a constituição ontológica do estar-aí é a de ser-no-mundo (In-der-Welt-sein), que remete a um fenômeno de unidade. "A expressão composta 'ser-no-mundo', já na sua cunhagem, mostra que pretende referir-se a um fenômeno de unidade" (HEIDEGGER, 2000, p. 90; 71).

O ser-em (In-Sein) de ser-no-mundo não indica a mesma coisa para o estar-aí e o ser simplesmente dado. Para este último caso, "designamos o modo de ser de um ente que está num outro, como a água está no copo, a roupa no armário" (HEIDEGGER, 2000, p. 91; 72). Pórem, no que diz respeito ao estar-aí, não podemos pensá-lo como uma coisa dentro da outra, pois na sua constituição ontológica o estar-aí é um existencial, o que implica que o ente que está "em" é sempre o meu próprio. Assim, não posso estar-dentro, só posso ser "junto a" (bei) ou me deter junto ao mundo do que já me é familiar (HEIDEGGER, 2000, p. 92; 73). 
É somente assim que uma presença pode ser junto ao mundo, ou seja, simplesmente dando-se a ocorrer em conjunto e não através de modos de justaposição. Dessa forma, o estar-aí de um ente é diferente do de um objeto, pois para que isso ocorra a um objeto seria necessário que um mundo já tivesse sido descoberto e vindo ao seu encontro.

O ser-no-mundo é condição de necessidade do estar-aí, pois ainda que ele se perca ou se encubra nos diferentes modos de ser da ocupação (Besorgen $)^{2}$, ele não está livre de ser-em, pois ser-no-mundo é uma constituição fundamental do estar-aí (HEIDEGGER, 2000, p. 95; 76).

A pergunta que se impõe, então, é: o que é este estar-aí na cotidianidade que não apenas está no mundo, mas que, também, com ele se relaciona?

O estar-aí é sempre o eu mesmo próprio que, como ente intramundano (um ser-no-mundo envolvido em modos diferentes de ocupação e preocupação) que sou, vou ao encontro dos outros. "Os outros" aqui não significa "todo o resto dos demais, além de mim, do qual o eu se isolaria. Os outros, ao contrário, são aqueles dos quais, na maior parte das vezes, ninguém se diferencia propriamente, entre os quais também se está" (HEIDEGGER, 2000, p. 169-70; 158).

Destaca-se, portanto, o caráter do que é dado em conjunto dentro do mundo. Este "com" (mit) abre a possibilidade de igualdade, ou seja, a possibilidade de compartilhar com os outros o seu ser-no-mundo. "O mundo do estar-aí é o mundo compartilhado [Mitwelt]. O ser-em é sercom [Mitsein] os outros. O ser-em-si intramundano destes outros é a copresença [Mitdasein]”' (HEIDEGGER, 2000, p. 170; 159).

O estar-aí, portanto, tem na determinação do seu próprio estaraí o ser-com, o que significa que, dentro do mundo, o estar-aí se libera na co-presença dos outros, pois "o próprio estar-aí só é na medida em que possui a estrutura essencial do ser-com, enquanto co-presença que vem ao encontro" (HEIDEGGER, 2000, p. 172; 161).

É por ser o ser-com entendido existencialmente que ele não pode se apresentar nos modos de ser dos entes que vêm ao encontro no mundo (ser simplesmente dado), isto é, nos modos de ocupação. O sercom não se ocupa, mas sim se preocupa (Fürsorge).

2 Como "ter o que fazer com alguma coisa, produzir alguma coisa, tratar (bestellen) e cuidar (pflegen) de alguma coisa (...) pesquisar, interrogar, considerar, discutir, deter$\operatorname{minar}(\ldots) "$ ".

Revista de Filosofia, Curitiba, v. 17 n.20, p. 45-66, jan./jun. 2005. 
O modo de ser do estar-aí é o da convivência, pois "mesmo quando cada estar-aí de fato não se volta para os outros, quando acredita não precisar deles ou quando os dispensa, ele ainda é no modo de ser-com." (HEIDEGGER, 2000, p. 175; 164).

Infelizmente, tivemos que fazer grandes recortes na abordagem dada por Heidegger à questão do sentido do ser em sua obra Ser e Tempo. Isso porque nem todas as questões levantadas por este filósofo nessa obra cabem aqui nesse estudo. Além disso, está ainda por ser trabalhada a questão que nos move nessa pesquisa: a angústia. Reservemos para ela a parte final deste trabalho, uma vez que a nossa leitura de Ser e Tempo ainda não foi finalizada.

O que gostaríamos de mostrar nesse momento é que a questão do ser investigada por Heidegger nos obriga a pensar o ente, o homem, ou o sujeito - como se costuma empregar no discurso psicanalítico - a partir de uma outra perspectiva. Com essa nova interpretação do ente (que na verdade é a mais antiga, pois a questão do ser já era a impulsionadora da filosofia grega), também é preciso repensar a questão do ser na psicanálise. Esse trabalho parece já ter sido começado na psicanálise de Winnicott.

Algumas são as afinidades possíveis existentes entre o pensamento desses dois grandes pensadores acerca do que é o homem, as quais, agora, gostaríamos de observar. Logo depois, consideraremos a questão da angústia tanto do ponto de vista ôntico como ontológico, a fim de trazer alguma contribuição positiva para o seu estudo e entendimento.

\section{Afinidades pós-metafísicas}

Ao contrário de Freud, Winnicott não procura basear suas explicações sobre a natureza humana no princípio de causalidade, nem enquadrá-las no âmbito determinista da ciência natural. Ele não vê o ser humano como um mecanismo, mas sim como alguém que demanda cuidado para alcançar o status de pessoa. Sobre este ponto se questiona Winnicott:

Um lactente é um fenômeno que pode ser isolado, ao menos hipoteticamente, para observação e conceitualização? Eu sugiro que a res-

Revista de Filosofia, Curitiba, v. 17 n.20, p. 45-66, jan./jun. 2005. 
posta é não. Quando voltamos os olhos para nossas análises de crianças e adultos tendemos a ver mecanismos ao invés de lactentes. Mas, se nós olharmos para o lactente veremos uma criança em cuidado (in care). O processo de integração, de separação, de começar a viver no corpo e de relacionar-se com objetos, estas são todas questões de amadurecimento e realização (1989, p. 74).

O que Winnicott procura, segundo Dias (1998), é escapar ao determinismo causal, por isso ele usa expressões do tipo: "no início, há apenas um bebê potencial que precisa tornar-se real". Isso quer dizer que o ser humano, desde o seu início, não é constituído por determinações intrínsecas que se manifestariam com o passar do tempo "Para começar, não há 'determinações' intrínsecas no bebê, sejam elas somáticas ou psíquicas. Com a única exceção da tendência à integração, todas as características possíveis precisam ser criadas" (DIAS, 1998, p. 97).

Em Winnicott, não estão em jogo as forças que levam a um efeito. O que está em jogo, ao que nos parece, é o deixar acontecer humano, isto é, deixar que o que ainda não é venha a ser, a partir de uma indeterminação de encontros possíveis que lhe possam advir.

A originação do ser humano, ou o seu amadurecimento, não é portanto um assunto que possa ser visto como efeito de uma causa. O poder do qual surge o poder-existir humano não é do tipo que efetua efeitos. É, antes, um deixar que o que ainda não é chegue a ser, que o que não está presente chegue à presença, que as possibilidades de ser venham à luz, lançadas, no entanto, na indeterminação da vida (DIAS, 1998, p. 94).

Surge, a partir dessa idéia de 'que o que ainda não é venha a ser', a questão de saber qual é o sentido do ser em Winnicott, isto é, qual é o ponto de partida desse autor para poder compreender o ser humano? Em Winnicott (1988), o ponto de partida do ser humano é o não-ser. Diz ele: "only out of non-existence can existence start." (p. 95)

Assim, o acontecer humano se dá entre o ser e o não-ser. A única coisa com a qual ele pode contar é com a sua tendência ao amadurecimento e à integração. "A vida de uma pessoa consiste num in tervalo entre dois esta dos de não-estar-vivo[unaliveness]" (WINNICOTT, 1988, p. 132).

Revista de Filosofia, Curitiba, v. 17 n.20, p. 45-66, jan./jun. 2005. 
Essas questões, dentre outras, como, por exemplo, procurar uma linguagem não-metapsicológica (metafísica) ou os diferentes sentidos de realidade que se encontram em sua obra, remetem-nos à fenomenologia-existencial de Heidegger que parece ter sido o primeiro a fazer tais questionamentos dentro da história da filosofia.

Não se tem notícia de que Winnicott tenha lido alguma vez qualquer obra de Heidegger. No entanto, é de se impressionar o quanto são afins suas concepções sobre o ser humano.

A pergunta pelo sentido do ser em Winnicott vai tão longe ou tão profundamente quanto em Heidegger. Nesse filósofo, a semântica da palavra "ser" deve ser entendida "num retorno à simplicidade originária" (LOPARIC, 1995, p. 47). Simplicidade já há muito tempo esquecida pela metafísica e há muito tempo desconhecida pela metapsicologia. Em Winnicott, essa semântica está referida à linguagem materna, àquela da intimidade originária do bebê (LOPARIC, 1995).

Assim, a questão de saber quem eu sou, para a psicanálise winnicottiana, é totalmente secundária, uma vez que vem depois. É preciso que, antes de tudo, se assegure ao ser que está surgindo, o bebê, o seu sentido de ser, através do seu continuar-a-ser. Para tanto, é preciso que a mãe deixe que esse bebê seja, "que constitua uma 'quantidade do simples ser' e que continue sendo, isto é, que aconteça” (LOPARIC, 1995, p. 49).

Podemos perceber que não se está falando de conflito pulsional no sujeito, nem de bom ou mau objeto ou de jogo de forças. Trata-se de cuidado (Sorge em alemão e care em inglês). A amostra mais nítida do que pode ser entendido por cuidado apresenta-se na preocupação matema primária, na qual a sintonia da mãe com seu bebê é tão grande que ela é capaz de compreender as suas necessidades. Embora esse exemplo de cuidado seja ôntico-existencial, ele já está de antemão referido a um fenômeno ontológico. O cuidaré um fenômeno ontológico fundamental, isto é, no fenômeno do cuidado, o homem preocupa-se com o seu próprio existir e com o existir em geral (HEIDEGGER, 2000, p. 174; 163). Isto porque o homem é um ser-no-mundo que, enquanto presença, é também um ser-com os outros que lhe permitem a abertura para a convivência. Vemos na preocupação matema primária o modo de ser onde os entes (tanto a mãe como o bebê) se manifestam desencobridoramente de forma originária.

"O homem heideggeriano existe como um estar-aí-no-mundo, que tem que cuidar desse seu estar-aí e do existir de todas as coisa sintramundanas" (LOPARIC, 1995, p. 57). 
Assim como Heidegger, Winnicott entende o homem como uma amostra-temporal da existência, e não como conjunto de causalidades mensuráveis e calculáveis. Isto significa dizer que:

"Winnicott vê a vida humana como um intervalo que contém em si mesmo dois términos (ends): o estado inicial de não-estar-vivo ou de pré-dependência e a 'segunda morte' ou o retorno ao estado inicial de não-estar-vivo" (apud LOPARIC, 1995, p. 124).

O homem surge do estado de não-ser para o de ser, e no final de sua existência, retorna ao estado de não-ser. Mas então, o que marca o seu período de acontecência (Geschichtlichkeit)? O cuidado para consigo mesmo e para com os outros? Não. Não é o cuidado, mas sim, a morte. $\mathrm{O}$ cuidado é apenas um modo de ser fundamental e originário, aberto por uma possibilidade mais fundamental e irremissível: a morte.

Nestes dois autores - Heidegger e Winnicott ( - a morte tornase, portanto, o parâmetro da vida, na medida em que todo o homem é um ser-para-a-morte (Sein zum Tode) (HEIDEGGER, 2000, p. 34-37; 335339). Dessa forma, todo ente que está-lançado no mundo já está sempre diante da possibilidade de sua impossibilidade mais própria, cuja propriedade está no fato de que não se pode morrer por outra pessoa, uma vez que a possibilidade de minha morte é sempre e unicamente minha. Em outras palavras, todo homem que está vivo no mundo já está sempre diante da possibilidade de não mais estar vivo agora neste mundo.

$\mathrm{O}$ fato de ser-para-a-morte abre para o ente várias outras possibilidades além de sua impossibilidade mais própria, tais como: o cuidar do seu próprio existir e do existir em geral, a angústia como desveladora originária do sentido do ser, e mesmo a possibilidade de esquecimento e encobrimento, através dos diferentes modos de ocupações no cotidiano, do próprio ser-para-a-morte.

Parece, então, que as concepções que Winnicott tem da natureza humana vão, de certa forma, ao encontro da questão do sentido do ser levantada por Heidegger.

Os dois comungam da idéia de que a compreensão do sentido do ser do homem e das coisas se dá num 'entre', num espaço-tempo, como entende Winnicott, ou no 'tempo-espaço', como diz Heidegger. Por fim, para ambos, o existir humano é caracterizado por uma relação íntima com o não-ser essencialmente finito (LOPARIC, 1995, p. 59).

Revista de Filosofia, Curitiba, v. 17 n.20, p. 45-66, jan./jun. 2005. 
Muitas questões poderiam ainda ser levantadas como, por exemplo, os diferentes sentidos de ser em Winnicott - onde a questão da realidade aparece prima facie - as contribuições ônticas de Winnicott para o pensamento heideggeriano ou mesmo as contribuições de Heidegger para uma ontologia winnicottiana.

Não trataremos dessas questões nesse momento, pois nosso objetivo aqui é mostrar certos paralelos e afinidades entre esses pensadores da questão do ser humano. Dessa maneira, poderemos justificar, no que segue, como abordar a questão da angústia tanto ôntica como ontologicamente na psicanálise.

\section{O desvelar pela angústia}

Alcançamos o momento em que poderemos abordar a angústia à luz da fenomenologia existencial. Partindo do campo semântico, a palavra angústia guarda em si muitos sentidos que, à primeira vista, parecem diferentes. Pode-se falar de angústia de castração, angústias impensáveis, angústia entendida como temor (Furcht) e angústia como disposição privilegiada.

Não analisaremos aqui o conceito de angústia de castração, embora esse tema seja retomado posteriormente nesse artigo. Apresentaremos, quando mesmo, rapidamente o conceito de angústias impensáveis. Procuraremos, porém, tratar da questão da angústia como fenômeno originário fundamental para o sentido do ser e do temor, pois esses conceitos nos levam diretamente aos pontos de intersecção entre a psicanálise de Winnicott e a filosofia de Heidegger. Tendo sido feito esse trabalho, então, poderemos ver que esses diferentes sentidos apresentados para a caracterização da angústia se relacionam e derivam do seu sentido mais originário.

Quanto às angústias impensáveis, pode-se dizer que elas são traumas localizados nos estágios iniciais do processo de amadurecimento humano, entendendo-se trauma, neste início, como quebra da continuidade na existência de um indivíduo. Depois de uma experiência traumática, defesas são organizadas a fim de evitar que as angústias impensáveis voltem a ser experienciadas. "Quando o padrão do ambiente é traumático", esclarece Elsa. O. Dias, "ocorre uma interrupção do processo de amadurecimento. As angústias impensáveis quebram a incipiente

Revista de Filosofia, Curitiba, v. 17 n.20, p. 45-66, jan./jun. 2005. 
integração, isto é, a incipiente experiência de um si-mesmo, de qualquer grau ou tipo, mas anterior à constituição de um eu, que existe por ocasião do fracasso ambiental" (DIAS, 1998, p. 255).

O trauma é constituído por uma reação automática do bebê à intrusão ambiental. Essa intrusão é traumática porque obriga o bebê a reagir ao invés de continuar-a-ser e esse continuar-a-ser é ameaçado pelas angústias impensáveis (DIAS, 1998). Elas "remetem ao perigo extremo de o indivíduo cair fora da existência, de que a existência enquanto tal não se dê ou se perca" (DIAS, 1998, p. 255).

Deve-se observar que essas intrusões ambientais, que podem levar o bebê a um reagir excessivo, "não produzem frustração, mas uma ameaça de aniquilação" (DIAS, 1998, p. 256). Não produzem frustração, pois esse é um sentimento bastante sofisticado que supõe a existência de alguém que já é capaz de desejar e frustrar-se em seu desejo. E nesse estágio inicial ao qual se refere a angústia impensável, o si-mesmo, o eu da pessoa ainda está em formação.

Essas angústias que estamos estudando podem ser definidas como impensáveis porque, por um lado, Loparic (1976) observa que "não são definíveis em termos de relações pulsionais de objeto, baseadas em relações representacionais de objeto (percepção, fantasia, simbolização)" e, por outro lado, "porque estamos nos referindo a um momento pré-verbal, pré-psíquico e pré-representacional, anterior ao início de qualquer capacidade relacionada a mecanismos mentais e muito anterior ao reconhecimento de impulsos instintuais como fazendo parte do simesmo e tendo um significado" (DIAS, 1998, p. 258).

Quanto ao temor (Furcht), do ponto de vista ontológico, segundo Heidegger, ele está relacionado com um ente que vem ao encontro dentro do mundo seja esse ente manual, simplesmente dado ou uma co-presença (Mitdasein) (HEIDEGGER, 2000, p. 195; 186). Mais do que temer algo, alguma coisa ou alguém, o que se teme, na verdade, é a ameaça. $\mathrm{O}$ ameaçar possui o caráter do aproximar-se que vem ao encontro numa região, trazendo consigo o dano. $\mathrm{O}$ danoso se aproxima sem poder ser dominado, podendo, em sua ameaça, chegar a realizar-se ou não.

A temeridade (Furchtbarkeit) que constitui o temer abre o mundo para que o que é temível possa se aproximar. Assim, o que se teme já é descoberto previamente pelo temer.

Revista de Filosofia, Curitiba, v. 17 n.20, p. 45-66, jan./jun. 2005. 
A circunvisão [Umsicht] vê o temível por já estar na disposição [Befindlichkeit] do temor. Como possibilidade adormecida do ser-no-mundo disposto, o temor é 'temerosidade' [Furchtsamkeit] e, como tal, já abriu o mundo para que o terrivel dele possa se aproximar (HEIDEGGER, 2000, p. 196; 187-188).

No entanto, esse temor é temor pelo quê?É temor pelo próprio estar-aí. Pois, sendo, já está em jogo o meu próprio ser. O estar-aí como ser-no-mundo apresenta-se, impropriamente, como ser de ocupações junto a e, por isso, a ameaça trazida pelo temor vai ao encontro do abandono de si mesmo.

O próprio ente que teme, o estar-aí, é aquilo pelo que o temor teme. Apenas o ente em que, sendo, está em jogo seu próprio ser, pode temer.(...) De início e na maior parte das vezes, o estar-aí é a partir do que se ocupa. Estar em perigo é a ameaça do ser e estar junto a (HEIDEGGER, 2000, p. 196; 188).

O temor é um modo da disposição. Onticamente, a disposição na cotidianidade mediana é conhecida por humor (Stimmung) que "designa o estado e a integração dos diversos modos de sentir-se, relacionar-se e de todos os sentimentos, emoções e afetos bem como das limitações e obstáculos que acompanham essa integração" (HEIDEGGER, 2000, p. 321). ${ }^{3}$ Em suma, a disposição revela "como se está". A disposição abre para o estar-aí o seu estar-lançado no mundo. Dessa forma, o estar-aí, como ente intramundano, pode ser ameaçador e como ser-em estar ameaçado. O que significa dizer que, como ser-no-mundo o temer coloca em perigo a presença do meu estar-aí, ao mesmo tempo em que é possível que o estar-aí dos outros entes possa ser ameaçado pela minha presença.

Mas, deixemos a questão do temor um pouco de lado e avancemos sobre a compreensão de como Heidegger analisa a questão da angústia.

Para a análise do conceito de angústia (Angst) em Heidegger, deve-se entender, primeiramente, que decadência (Verfallen) é um modo fundamental de ser da cotidianidade, mas que nem por isso ela deve ser compreendida de forma negativa. A decadência indica que o estar-aí está

${ }^{3}$ Nota explicativa da tradução para o português do termo Stimmung. 
junto ao "mundo" das ocupações. Isto que dizer que o estar-aí como serno-mundo decaiu em um "mundo" que é conduzido pelo falatório, pela curiosidade e pela ambigüidade, ou seja, o estar-aí decaiu nos modos de ser cotidianos do discurso, assegurados, em seu convívio com os outros e com as coisas, pelo modo de ser do impessoal das pessoas.

Assim, nos divertimos e nos entretemos como impessoalmente [man] se faz; lemos e julgamos sobre a literatura e a arte como impessoalmente se vê e julga; também nos retiramos das 'grandes multidões' como impessoalmente se retira; achamos 'revoltante' o que impessoalmente se considera revoltante. O impessoal [man], que não é nada determinado mas que todos são, embora não como soma, prescreve 0 modo de ser da cotidianidade (HEIDEGGER, 2000, p. 179; 169).

O estar-aí em seu modo de decadência se perde no impessoal, foge de si mesmo, isto é, foge do seu poder-ser mais próprio, desvia-se da questão do ser e se lança para fora de si mesmo nos variados modos de ocupação intramundanos. O estar-aí foge de si mesmo, pois já está aberto para ele, enquanto ser-no-mundo, o fato de o estar-aí já se colocar sempre diante de si mesmo."É justamente daquilo de que foge que 0 estar-aí corre 'atrás'” (HEIDEGGER, 2000, p. 248; 245).

A palavra "fuga" assume dois sentidos diferentes quando relacionada ao temor ou à decadência. Quando a fuga está relacionada ao temor, ela denota o retirar-se, o desviar-se daquilo que desencadeia 0 temor, ou seja, do que é ameaçador, pois, no temor, "aquilo que se teme é sempre um ente intramundano que, advindo de determinada região, torna-se de maneira ameaçadora, cada vez mais próximo" (HEIDEGGER, 2000, p. 249; 247). Na decadência, "fuga" significa fuga de si mesmo pelo fato do estar-aí decair no impessoal e no "mundo" das ocupações. Nesse sentido, o retirar-se, o desvio, não diz respeito ao que vem ao encontro como ente intramundano. Este modo da fuga baseia-se em uma situação prévia, anterior ao próprio temor pelo estar-aí. “O desvio da decadência [Verfallen] se funda na angústia [Angst] que, por sua vez, torna possível o temor" (HEIDEGGER, 2000, p. 249; 247).

Desse modo, já se sabe que aquilo com quê a angústia se angustia não é do mesmo gênero daquilo que o temor teme. $\mathrm{O}$ com quê da angústia não tem a ver com o ente intramundano. Em verdade, "o com quê da angústia é indeterminado (unbestimmt)" (HEIDEGGER, 2000, p. 250; 247).

Revista de Filosofia, Curitiba, v. 17 n.20, p. 45-66, jan./jun. 2005. 
Esse caráter indeterminado da angústia coloca o manual e o ser simplesmente dado numa posição irrelevante. "Nada do que é simplesmente dado [vorhanden] ou que se acha à mão [zuhanden] no interior do mundo serve para a angústia com ele angustiar-se" (HEIDEGGER, 2000, p. 250; 247).

O que serve, então? Para responder a essa questão, devemos notar que o quê (Wovor) na angústia é ameaçador, não se encontra em lugar algum. "Ela não sabe o que é aquilo com que se angustia” (HEIDEGGER, 2000, p. 250; 248).

O que ameaça não tem um modo de aproximação determinado; a ameaça está sempre presente e ao mesmo tempo não está em lugar algum. Na angústia originária, "o ameaçador dispõe da possibilidade de não se aproximar a partir de uma direção determinada, situada na proximidade, e isso porque ele já está sempre 'presente' (da), embora em lugar algum. Está tão próximo que sufoca a respiração, e, no entanto, em lugar algum" (HEIDEGGER, 2000, p. 250; 247). Em conseqüência, podese dizer que: "Aquilo com que a angústia se angustia é o 'nada' que não se revela 'em parte alguma'”, portanto, "a angústia se angustia com 0 próprio ser-no-mundo” (HEIDEGGER, 2000, p. 250-251; 247-248).

Contudo, precisamos ir mais devagar, pois do "nada" a angústia se tornou 'angústia com o próprio ser-no-mundo'. Como isso se explica? O "nada" e no "em parte alguma" que caracterizam a angústia não significam a ausência do mundo, apenas revelam que o "ente intramundano em si mesmo tem tão pouca importância que, em razão dessa insignificância do intramundano, somente o mundo se impõe em sua mundanidade" (HEIDEGGER, 2000, p. 250; 248).

A angústia se angustia com o ser-no-mundo como tal (HEIDEGGER, 2000, p. 249; 247). Isso quer dizer que a angústia é a possibilidade de abertura originária e direta do mundo como mundo, isto é, mundo como possibilidade de tudo o que está à mão. A abertura do mundo como mundo significa que "não é primeiro a reflexão que abstrai do ente intramundano para só então pensar o mundo e, em conseqüência, surgir a angústia nesse contexto" (HEIDEGGER, 2000, p. 251; 248). Deve-se deixar o cartesianismo de lado. O que Heidegger afirma é que a partir da angústia é que o ente intramundano adquire o seu significado e importância.

A angústia, nesse sentido originário, não tem apenas um com quê (Wovor), mas também um "pelo quê" (Worum). Nesse pelo quê, a 
angústia se angustia pelo seu próprio ser-no-mundo. Na angústia, a ameaça é indeterminada. $\mathrm{O}$ que se encontra à mão, assim como o ente intramundano, se perde. Na angústia pelo próprio ser-no-mundo "o 'mundo' não é mais capaz de oferecer alguma coisa nem sequer a co-presença dos outros" (HEIDEGGER, 2000, p. 251; 248).

Desempenhando dois papéis importantes para o caráter existencial do estar-aí a angústia, ao mesmo tempo em que revela o ente intramundano no modo de ser da decadência - pois revela o estar-aí decaído no "mundo" de modo impessoal, impróprio - ela também oferece a possibilidade de retirar o estar-aí de seu modo impróprio de ser, uma vez que abre para ele o seu próprio poder-ser-no-mundo finito. Por conseqüência: "no estar-aí, a angústia revela o ser para o poder-ser [Seinkönnen] mais próprio, ou seja, o ser livre para a liberdade de assumir e escolher a si mesmo" (HEIDEGGER, 2000, p. 252; 249-250).

Parece que temos, nesse momento, para os objetivos propostos neste trabalho, base suficiente para podermos discutir a angústia da perspectiva ôntica e ontológica e do ponto de vista da sua semântica, termo esse aqui entendido como o estudo das mudanças ou variações sofridas, no tempo e no espaço, da significação das palavras.

Quanto ao seu significado, acreditamos que a angústia de castração de Freud representa, onticamente, o sentido que o termo temor possui quando analisado existencialmente. Freud, ele mesmo, várias vezes usa um termo pelo outro, isto é, por vezes usa a palavra alemã Furcht em lugar de Angst e vice-versa (HANNS, 1996, p. 62-79). Heidegger reconhece nessas duas palavras um certo parentesco fenomenal e, acerca disso, comenta:

O indício de parentesco é o fato de ambos os fenômenos permanecerem, na maior parte das vezes, inseparáveis um do outro e isso a tal ponto que se chama de angústia o que é temor e se fala de temor quando o fenômeno possui o caráter de angústia (HEIDEGGER, 2000, p. 196; 188).

A angústia de castração, assim como os temores, são constituídos pelo caráter da ameaça do que vem ao encontro do ente intramundano. Em Freud é a ameaça de castração que é o temível, isto é, aquilo pelo que se teme, e não a castração propriamente dita. Já em Heidegger, o que se teme é a ameaça ao ente intramundano que pode possuir 0 modo de ser do manual, do ser simplesmente dado ou ainda de uma co-

Revista de Filosofia, Curitiba, v. 17 n.20, p. 45-66, jan./jun. 2005. 
presença. Heidegger afirma que “o próprio ente que teme, o estar-aí, é aquilo pelo que o temor teme. Apenas o ente em que, sendo, está em jogo seu próprio ser, pode temer" (HEIDEGGER, 2000, p. 196; 188). Nesse sentido, a angústia de castração pode ser entendida como um fenômeno ôntico-existenciário que denuncia o modo de ser impróprio do ser-no-mundo expresso pelo temor no estar-aí.

As angústias impensáveis e a angústia tal como entendida por Heidegger também parecem possuir afinidades. Em ambas, o que caracteriza a angústia é o fato de aquilo que é ameaçador não se encontrar em lugar algum e essa ameaça vir de todas as direções e de direção nenhuma. Em ambas está em jogo o sentido do ser.

No entanto, deve-se observar que o conceito de angústia em Heidegger não é a tradução do conceito de angústia em Winnicott. Todavia, podemos observar que há uma correlação de sentido entre eles. A diferenciação está em que, para Heidegger, a angústia é uma disposição privilegiada que abre para o ser do estar-aí a sua possibilidade de ser mais própria, isto é, abre o seu poder-ser-no-mundo próprio finito como a sua possibilidade mais originária e fundamental. A angústia é aí analisada sob a perspectiva da ontologia fundamental.

No caso de Winnicott, a angústia está associada a uma falha no cuidado materno que abre para o ser que está surgindo a possibilidade de seu aniquilamento, não querendo isso dizer que esse ser se perde e se desvia nos modos impróprios de ser, no esquecimento do ser dos diferentes modos de ocupação. Aniquilamento aqui quer dizer que 0 bebê pode nunca chegar a ser, ou seja, que o seu sentido de ser foi perdido, que a sua continuidade-de-ser foi quebrada. Assim, diríamos que essa análise é ôntico-existencial.

Embora a análise do conceito de angústia se dê em níveis diferentes de interpretação, isto é, há uma interpretação ontológica e uma ôntica, trata-se, em última instância, da análise de um mesmo fenômeno: a angústia. Por um lado, a interpretação ontológica nos revela a angústia como possibilitadora da compreensão do sentido do ser, ou seja, ela abre para o ente o modo mais originário de existir durante sua existência. Por outro lado, a interpretação ôntica nos remete ao fenômeno da angústia que pode acometer o ser de cada um, isto é, ela remete à angústia fatual, está relacionada aos vários modos de ser da existência humana como a angústia de castração, angústia pela perda de alguém ou alguma coisa, angústia diante do envelhecimento, entre outras. Nota-se, 
portanto, que em ambos os tipos de análise, o fenômeno que está presente é sempre o da angústia. Todavia, a compreensão da análise ontológica da angústia é essencial para o entendimento desse mesmo fenômeno na interpretação ôntica.

Heidegger nos autoriza a pensar dessa forma quando diz que a angústia já está previamente colocada em toda discussão sobre o ser. Portanto, até para um bebê, é a angústia originária que abre a possibilidade para o seu sentido de ser, isto é, o seu continuar-a-ser.

Com freqüência, a angústia é condicionada 'fisiologicamente'. Em sua facticidade, esse fato é um problema ontológico e não apenas no que respeita a sua causalidade e processamento ônticos. O disparo psicológico da angústia só é possível porque o estar-aí, no fundo do seu ser, se angustia" (HEIDEGGER, 2000, p. 254; 252).

Em conseqüência do que se seguiu até aqui, procuraremos, agora, mostrar que a angústia de castração, em sua relação com a angústia impensável, pode ser entendida como uma denivação e forma de esquecimento desta última.

Ao relacionarmos a angústia de castração com o temor, tal como entendido por Heidegger, percebemos que ela é um modo impróprio e deficiente do ser do ente se apresentar como ser-no-mundo, isto é, o estaraí como ser-no-mundo apresenta-se "doente" em seu modo de ser-com os outros, no modo de ser da co-presença, e, por causa da ameaça ao seu estaraí, ele foge de si mesmo, perdendo-se e esquecendo-se nos vários modos (neuróticos) de ser da ocupação. Do ponto de vista da fenomenologia existencial, a angústia de castração é a representação fatual de uma afecção psíquica do ser humano que, revelada pela análise fenomenológica, mostra sua relação com a questão do temor que, por sua vez, está ligada à questão do sentido do ser aberta pela análise da angústia originánia.

Como a angústia já sempre determina, de forma latente, o ser-nomundo, este, enquanto ser que vem ao encontro na ocupação junto ao 'mundo', pode sentir temor. Temor é angústia imprópria, entregue à decadência do 'mundo' e, como tal, angústia nela mesma velada (HEIDEGGER, 2000, p. 254; 252).

A análise heideggeriana da angústia originária permitiu-nos observar que a questão do sentido do ser encontra-se já presente desde 0

Revista de Filosofia, Curitiba, v. 17 n.20, p. 45-66, jan./jun. 2005. 
início do acontecer humano, isto é, do ponto de vista ôntico, desde quando já se é um bebê. Observamos que a angústia mais primordial a que um bebê pode estar sujeito é aquela que Winnicott chamou de angústia impensável. Esta angústia se nos revelou como um conceito de importância capital, pois é a que melhor descreve, no nível ôntico, na fatualidade da existência humana, o que Heidegger explicita ontologicamente. Pois, assim como a angústia originária, a angústia impensável abre para o ser que está surgindo a questão do seu sentido de ser, ou seja, o continuar-a-ser em direção a uma unidade integral, ou o fragmentar-se, ou pior, aniquilar-se, permanecendo sempre como um não-ser.

Isto nos permite observar que a angústia de castração só pode existir diante do pressuposto de que anteriormente já se colocou para 0 homem a questão do sentido de ser, que, em sua origem, está relacionada com uma angústia mais primordial: a angústia impensável. Esta, por sua vez, remete-nos à angústia originária e fundamental do estar-aí que lhe abre como ser-no-mundo a sua possibilidade da impossibilidade de não mais estar-aí, ou seja, a morte, o não-ser.

\section{Considerações Finais}

Olhar a psicanálise da perspectiva do acontecer humano talvez provoque uma série de questionamentos por parte daqueles que vêm seguindo o desenrolar deste artigo. Por um lado, porque esse tipo de abordagem ainda não está consolidada e este trabalho, pela restrição de espaço que se nos impõe, não consegue abranger, em grande profundidade todos os aspectos que a abordagem fenomenológica existencial poderia oferecer. Por outro lado, as questões podem surgir por causa da formação de compromisso que se estabelece com os paradigmas psicanalíticos vigentes.

Mesmo assim, não há como fugir de algumas questões que poderiam surgir após a leitura desse trabalho. Nós mesmos gostaríamos de adiantar duas delas e tentar proporcionar algum esclarecimento.

As angústias impensáveis são mais importantes que a angústia de castração? Qual o critério que se segue para se decidir sobre isso?

Podemos dizer que tanto as angústias impensáveis quanto a angústia de castração são muito importantes no desenrolar da vida do ser humano. Não há como destacar um grau de importância de uma em 
relação à outra do ponto de vista da teoria do amadurecimento. Segundo Winnicott, se o ser que está surgindo, o bebê, recebe um cuidado suficientemente bom por parte de sua mãe (ou mãe substituta), ele vai ter a sensação de um continuar-a-ser constante. Porém, se alguma falha acontecer, esse bebê sofrerá angústias impensáveis. Ora, essa é uma fase pela qual o bebê pode passar durante o início de seu processo de amadurecimento. Agora, se supusermos que esse bebê passou bem por essa fase inicial, ou mesmo que conseguiu, de alguma forma, superar as falhas e que, no desenrolar de seu processo de amadurecimento, chegou à fase de concernimento, ou seja, é capaz de preocupar-se e sentir sentimentos de culpa, então estaremos diante de um bebê em condições de lidar com seus sentimentos de amor e ódio, com as suas pulsões. Isso quer dizer que esse bebê tem saúde o suficiente para enfrentar angústias relacionadas ao temor de castração, entre outras. Como se pode notar, essa é uma outra fase. Portanto, tanto as angústias impensáveis, como a de castração, podem desempenhar um papel importante na vida do ser humano, porém deve-se resguardar a cada uma delas o seu momento no acontecer humano.

Por outro lado, quando relacionamos a angústia impensável à angústia originária do existir humano, ela se torna mais importante que a angústia de castração. Porém, antes de continuar, devemos reafirmar que o critério para essa decisão é semântico.

A angústia na fenomenologia existencial tem um caráter ontológico, isto é, diz respeito à questão do sentido do ser. Logo, à primeira vista, ela pareceria não ter nenhuma relação com a angústia impensável, já que esta tem um caráter ôntico. No entanto, pensamos que é exatamente o contrário e que uma diz respeito à outra com relação à compreensão do acontecer do ser humano no mundo. É através de uma interpretação de seus significados que podemos correlacioná-las.

Por um lado, a angústia originária, revelada pela questão do sentido de ser, abre para o ser humano a possibilidade de sua impossibilidade mais própria, ou seja, a sua morte. Por outro lado, na interpretação ôntica, observamos que as angústias impensáveis provocam uma interrupção no sentido de ser do lactente, isto é, interrompem o seu continuar-a-ser, provocando neste ser que estava surgindo de forma contínua, ou seja, a sensação de aniquilamento. Desse modo, pensamos que a angústia impensável é mais primordial - no sentido de que vem primeiro - que a angústia de castração.

Revista de Filosofia, Curitiba, v. 17 n.20, p. 45-66, jan./jun. 2005. 
Onticamente, as angústias impensáveis são as que melhor exemplificam o que Heidegger está querendo dizer com angústia originária. Ambas as formas de angústia correlacionam-se quanto ao sentido do ser, seja porque uma abre a possibilidade da morte pela impossibilidade de estar-aí, seja porque essa morte se revela na impossibilidade de integração e aniquilamento (WINNICOTT, 1996, p. 47) ${ }^{4}$. Heidegger expressa essa idéia da seguinte forma: "'Estamos suspensos' na angústia. Melhor dito: a angústia nos suspende porque ela põe em fuga o ente em sua totalidade.(...) Somente continua presente o puro ser-aí no estremecimento deste estar suspenso onde nada há em que apoiar-se." (HEIDEGGER, 1969, p. 32).

Finalmente, uma última questão: pensar as angústias impensáveis ou tratar de uma angústia originária não remete à questão da origem? Essa idéia não é metafísica?Como então querer sustentar, por exemplo, que Freud está inserido na tradição metafísica e Winnicott no pensamento pós-metafísico?

Quando nos referimos à metafísica, devemos fazer notar que temos em mente aquela forma de pensamento em que o ente é identificado com o que é atual, ou seja, com a objetivação das coisas. A ciência moderna parece ser quem melhor expressa esse modo de objetivação calculadora do ente. Esse caráter objetivante oferece a garantia de compreensão do ente e parece esgotá-lo em todas as suas possibilidades, de modo a se acreditar que se está de posse sobre a verdade do ser. Esse é o engano da metafísica, pois ela "conceitua a entidade do ente. Na entidade do ente pensa a metafísica o ser, sem, contudo, poder considerar, pela sua maneira de pensar, a verdade do ser" (HEIDEGGER, 1969, p. 48). A metafísica acredita que trata da verdade do ser quando, na verdade, trata da verdade do ente, por isso é necessário que se pergunte pelos seus fundamentos. Para isto, "este interrogar deve pensar metafisicamente e, ao mesmo tempo, deve pensar a partir dos fundamentos da metafísica, vale dizer, não mais metafisicamente" (HEIDEGGER, 1969, p. 48).

Heidegger questiona o sentido do ser e busca a sua origem. Nessa busca, ele questiona o que é o nada e descobre que ele é manifestado pela angústia. Da mesma forma, encontramos em Winnicott essa preocupação com a questão da origem, sendo as angús-

4 Cabe esclarecer que, para Winnicott, no início da vida do lactente a palavra morte tem um sentido figurado. É morte para nós que olhamos o bebê, pois "a morte não tem sentido até a chegada do ódio e do conceito de uma pessoa humana completa". 
tias impensáveis reveladoras da quebra do continuar-a-ser do ser humano em seu início e do nada, no qual este ser pode se encontrar. Dessa forma, ao deixar de pensar a questão do início do ser humano de modo objetivante e calculador, Winnicott se colocou do mesmo lado que Heidegger, questionando os fundamentos da metafísica por meio de um pensamento originário que supera a própria metafísica. "O pensamento originário que retorna ao fundamento da metafísica, somente pode fazê-lo porque su perou o objetivismo da metafísica que confundiu o ser com o en te e não pensa o próprio ser" (STEIN, 1969, p. 28).

\section{Referências}

DIAS, Elsa. O. A Teoria das psicoses em D. W. Winnicott. 1998. Tese (Doutorado em Psicologia Clínica) - Pontifícia Universidade Católica de São Paulo, SP,1998.

HANNS, Luís. Dicionário comentado do alemão de Freud. Rio de Janeiro, RJ: Imago, 1996.

HEIDEGGER, Martin. O que é metafísica. São Paulo,SP: Duas Cidades, 1969.

. Sein und Zeit: Gesamtausgabe. Frankfurt: Vittorio Kloestermann, 1977. v. 2.

. Ser e tempo. Petrópolis, RJ: Vozes, 2000.

LOPARIC, Zeljko. Heidegger and Winnicott. Revista. Natureza Humana, v. 1, n. 1, 1999.

. Winnicott e o pensamento pós-metafísico. Revista Psicologia ŪSP, v. 6, n. 2, São Paulo, SP: 1995. $17,1996$.

Winnicott: uma psicanálise não-edipiana. Revista Percurso, $n$.

SANTOS, Eder. S. As angústias impensáveis em relação à angústia de castração. 2001. Dissertação (Mestrado em Filosofia) - Universidade Estadual de Campinas, 2001.

Revista de Filosofia, Curitiba, v. 17 n.20, p. 45-66, jan./jun. 2005. 
STEIN, Ernildo. Nota do tradutor. In: HEIDEGGER, M. O que é metafísica. São Paulo,SP: Duas Cidades, 1969.

WINNICOTT, Donald. W. Psycho-analitic Explorations. USA: Harvard, University Press, 1989.

. Human nature. New York: Brunner: Mazel, 1988.

Recebido em: Received in: 30/11/2004 Aprovado em: Approved in: 20/02/2005 